\title{
Acetylcholinesterase Activity in the Human Thymus during Immune Response
}

\author{
Daniela Cavallotti, Marco Artico ${ }^{1}$ and Carlo Cavallotti ${ }^{2}$ \\ II Neurological Clinic- ${ }^{-}$Chair of Human Anatomy, Faculty of Pharmacy-2Department of Cardiovascular and Respiratory \\ Sciences, Section of Anatomy-University of Rome "La Sapienza", Italy \\ (Received 1 June 1999; and accepted 28 July 1999)
}

\begin{abstract}
The purpose of this paper is to study the amounts of acetylcholinesterase (AChE) activity during the immune response in the human thymus. AChE activity was analysed by biochemical and histoenzymatic methods in 7 immunostimulated (treated) and 7 non-immunostimulated (untreated) patients. Immunostimulation was obtained using the interferon drug for 6 months. After histoenzymatic staining of $\mathrm{AChE}$ activity, the slides containing the samples of thymus of treated and untreated patients underwent quantitative analysis of images. The results provide direct evidence that the immune response increases the level of AChE-positive structures contained in the human thymus. Treatment with interferon is also capable of increasing the protein content of the thymus. The biochemical data together with the histoenzymatical result, provide direct evidence for a specific localization of $\mathrm{AChE}$ in structures resembling nerve fibers and/or in lymphatic structures of the thymic gland.
\end{abstract}

There is a functional link between the nervous, the endocrine and the immune systems as demonstrated by recent studies on this topic $(19,22)$. The thymus, both in humans (5) and in other mammals $(8,13)$, is the unique organ that simultaneously possesses nervous, endocrine and immune functions in the same site. In man the immunological and the neuroendocrine functions change during aging and in some diseases $(11,12$, 14).

The thymic age-dependent involution is accompanied by alterations in the parasympathetic or cholinergic innervation $(3,4)$.

The present experiments were undertaken to investigate whether the immune stimulation with interferon drug in humans is able to modify the alterations induced by age in the cholinergic

* Correspondence to: Dr Carlo Cavallotti at above address

Tel: +39-06-4958291 Fax: + 39-06-4957669

E-mail:cameroni@uniromal.it innervation of the thymus.

\section{MATERIALS AND METHODS}

Immune stimulation of patients

In our city, many neurological hospitals are authorised as national data points for the study of multiple sclerosis (MS). In these hospitals, patients with MS are enrolled and treated by interferons. Recently, human recombinant $\beta$ interferon (Serobif Serono SPA-Italy) has been introduced into clinical practice as an immunomodulating systemic agent.

This drug belongs to the family of cytokines, natural proteins which also act as neurotransmitters/neuromodulators by exerting an immunostimulating or immunomodulating action. Cytokines comprehend a number of biologically active substances. The above-mentioned interferon can be employed in the treatment of patients affected by recurrent-remittent MS, whose clinical history is marked by at least two episodes of neurological 
involvement during the previous two years. In order to study the possible involvement of the thymus gland in MS, 14 patients with MS or other diseases (i. e. myasthenia gravis) and treated $(\mathrm{n}=$ 7) or untreated $(n=7)$ with interferon drugs, underwent a surgical biopsy of the thymus. Small fragments of these thymic biopsies drawn from seven immunostimulated patients, of different ages as well as from seven non-immunostimulated patients, were thus available for our experiments. Our study was approved by the Ethical Committees of the hospitals involved in this study and patients also gave their informed written consent. In National Clinical Centers the following therapeutic procedure was employed for administration of interferon. Patients enrolled 25, treated for six months (the drug is still completing the official registration course required by the Italian Health Authorities) by means of three intradermal or intramuscular injections of SerobifHuman recombinant $\beta$ interferon-corresponding to $6.000 .000 \mathrm{IU}$ weekly.

\section{Thymic biopsies}

Seven patients of this group ( 4 adults with an age of 24-55 years and three aged between 56-66 years) underwent surgical thymic biopsies. Another group of patients affected by other diseases and not treated by immuno-stimulating interferons were considered as control group. Seven of these patients also underwent diagnostic thymic biopsy. Samples coming from these equally aged patients were considered as untreated and served as the control group. Small fragments of all these biopsies were carried quickly, under dry ice, to our laboratories where they were submitted to the experimental procedures described.

\section{Histoenzymatic staining of $A C h E$}

For the demonstration of cholinergic structures the thymic biopsies (obtained from fresh tissue) were fixed in a $10 \%$ formaline-containing $1 \%$ calcium chloride solution ( $1 \mathrm{~min}$ ) (16) and then all sections were processed according to the direct-coloring thiocholine method (9). Isooctamethylpyrosphoramide (Iso-OMPA, Sigma) was used as the inhibitor of non-specific cholinesterase activity, because it inhibits peripheral aspecific cholinesterase without pronounced effects on the specific acetylcholinesterase in the central nervous system (6). The staining of an enzymatic activity requires numerous controls: after performing all these controls (absence of substrate, use of specific inhibitors, denaturation of reaction sites etc.) the identification of an enzyme requires also a biochemical analysis. For these reasons, in all the histoenzymatic findings described as results in this work, histoenzymatic staining was associated with biochemical analysis. The techniques presently available for an accurate histoenzymatic staining of cholinergic nerve fibers consist of visualizing the enzymatic activities correlated with acetylcholine synthesis and/or catabolism. These techniques are not very reliable and therefore do not allow a satisfactory quantitative assay of this enzyme. Consequently, our results are significant only from a comparative point of view.

\section{Estimation of protein content}

In all these experiments samples of thymus coming from the autopsies were weighed and placed on dry ice, (specimens for AChE histoenzymatic staining) or into an ice-cold homogenisation buffer (samples for estimating the protein content and the AChE activity). Tissue protein concentrations were determined by the method described by Lowry and coworkers (10) using bovine serum albumin (BSA) as standard.

\section{Biochemical evaluation of $A C h E$}

The AChE activity was measured by the colorimetric method of Ellman and coworkers (7). This method is designed for determination of tissue $\mathrm{AChE}$ activity, and its main principle is that thiocholine formed during hydrolysis of substrate rapidly reacts with DTNB (5,5'dithiobis-2-nitrobenzoic acid) and releases a colored 5-thio-2-nitrobenzoate anion having an absorption maximum at $416 \mathrm{~nm}$. The supernatant obtained after spinning the thymus homogenate (for $20 \mathrm{~min}$. at $3000 \mathrm{r}$. p. m. in a refrigerate centrifuge) was mixed with DTNB-phosphate buffered solution, and the reaction was started by adding $20 \mu \mathrm{L}$ of acetylcholine iodide $(1 \mathrm{mmol} /$ $\mathrm{L})$. The increase in absorbance of the reaction mixture was read every minute $(\Delta \mathrm{e} / \mathrm{min})$ for $15-$ $20 \mathrm{~min}$ at $416 \mathrm{~nm}$ and the mean value was calculated. The AChE activity is expressed in International Units (IU=nanomoles of substrate hydrolysed per minute per $\mathrm{mg}$ of protein). 
There are now more sophisticated and precise techniques for the identification and quantitative evaluation of enzymatic activities (immunohistochemistry, immunoelectron microscopy, PCR techniques, immunoblotting, ELISA, HPLC and so on). Nevertheless, many of these can be only applied on fresh homogenates and not on the small fragments harvested at surgical biopsies. Moreover, many tissues (including the thymus) require a pre-fixation that makes application of these new techniques impossible. For this reason we have adopted traditional enzymatic techniques but, as a new finding, we have performed the quantitative analysis for these histoenzymatic reactions.

\section{Staining of nerve fibers}

Nervous structures were coloured by the method described by Bodian (1). This method can be used to verify that a stained structure is nervous in nature: in fact, it stains nerve fibers and neurofibrils. After fixation in Bouin's fluid, sections were treated with: 1) $1 \%$ Protargol solution (colloidal silver); 2) reducing solution (Hydroquinone+ sodium sulphite); 3) 1\% Gold chloride solution; 4) $2 \%$ Oxalic acid solution and counterstained with $0.03 \%$ aniline blue. The nerve fibers and neurofibrils are black in colour.

\section{Staining of thymic microanatomical details}

The microanatomical details of thymic tissue were detected with Eosin-orange. After fixation, sections were treated with a working solution of Eosin-orange (20). Eosin gamma water-soluble 10 $\mathrm{g}$ was dissolved in $1000 \mathrm{~mL}$ of distilled water plus $2 \mathrm{~mL}$ of glacial acetic acid in order to obtain the stock solution. $25 \mathrm{~mL}$ of stock solution $+75 \mathrm{~mL}$ of $\mathrm{H}_{2} \mathrm{O}+0.5 \mathrm{~mL}$ of glacial acetic acid make the working solution-.

\section{Quantitative analysis of images}

In order to evaluate the histoenzymatic content of $\mathrm{AChE}$, a quantitative analysis of the intensity of histochemical staining was performed on slides by means of a Quantimet Analyzer (Leica ${ }^{(\mathbb{2}}$ ). The values of control sections, incubated without substrates, were considered as "zero". Examinations were performed separately for each slice, evaluating the standard error of the mean (S. E. M.). The results obtained by Quantitative Analy- sis of Images (Q. A. I.) may be incorrect because the main choices (the instructions for software) are ordered by each research-worker, according to personal preferences. For these reasons, the data are partial rather than impartial and it is necessary to follow very careful rules. The counts must be repeated at least three times using the doublemasked technique. All the counts should be performed by different research-workers, on different analysers, and with samples identified only by a number or by a letter. Final results must be obtained by another research-worker, who examines experimental protocols to identify each sample and attribute specific values. Final values must be submitted to statistical analysis of data. The values reported in this paper (see Results) represent the intensity of staining for each sample and are expressed in conventional units (C. U.) \pm S. E. M.

\section{Statistical analysis of data}

The statistical methods used throughout this study must be interpreted as an accurate description of the data rather than a statistical inference of such data.

The preliminary studies of each value were performed with the use of basic sample statistics. Mean values, maximum and minimum limits, variations, standard deviation (S. D.), standard error of the mean (S. E. M.) and correlation coefficients were performed according to Serio (17). The relationship between each pair of variables was studied using the respective correlation coefficients grouped in a correlation matrix, thus enabling us to study the existence of a lineal (values next +1 or -1 ) or non-lineal (values next +0 ) dependency. Finally, a correlative analysis of the morphological and biochemical data was performed by comparing the significant differences for each age group with the corresponding values of the other homogeneous groups. Correlation coefficients denote a significant level less than $0.001 \quad(P<0.001)$ while the correlation coefficient is not significant when $P>0.05$ (n. s.). This correlation coefficient was calculated according to Castino and Roletto (2).

\section{RESULTS}

Our results are reported in Figs. 1-6 and summarized in Tables 1-3.

Fig. 1 shows that in an untreated young man 
Table 1 Protein content in homogenates of thymus of adult and old patients treated and untreated with interferon

\begin{tabular}{lcc}
\multicolumn{1}{c}{ Thymus } & $\begin{array}{c}\text { Untreated } \\
\mathrm{n}=7\end{array}$ & $\begin{array}{c}\text { *Treated with interferon } \\
\mathrm{n}=7\end{array}$ \\
\hline $\begin{array}{l}\text { Adult patients } \\
\text { Age 24-55 } \\
\mathrm{n}=4\end{array}$ & $15.8 \pm 0.19$ & $19.6 \pm 0.22^{\circ}$ \\
\hline $\begin{array}{l}\text { Old patients } \\
\text { Age 56-66 } \\
\mathrm{n}=3\end{array}$ & $10.4 \pm 0.13$ & $12.8 \pm 0.18^{\circ}$ \\
\end{tabular}

Results are expressed as $\mathrm{mg} / \mathrm{g}$ fresh tissue weight. Each value is the mean value $\pm S$. D. of independent determinations from $n$. patients, carried out in triplicate.

$\mathrm{n}=$ number of patients; ${ }^{\circ} \boldsymbol{P}<0.001$ treated versus untreated. *Treatment of patients with interferon was performed as reported in Methods.

Table 2 Biochemical dosage of AChE activity in thymus (supernatant from homogenate) of adult and old patients treated and untreated with interferon

\begin{tabular}{lcc}
\hline \multicolumn{1}{c}{ Thymus } & $\begin{array}{c}\text { Untreated } \\
\mathrm{n}=7\end{array}$ & $\begin{array}{c}* \text { Treated with interferon } \\
\mathrm{n}=7\end{array}$ \\
\hline $\begin{array}{l}\text { Adult patients } \\
\text { Age 24-55 } \\
\mathrm{n}=4\end{array}$ & $36.3 \pm 2.14$ & $51.4 \pm 2.84^{\circ}$ \\
\hline $\begin{array}{l}\text { Old patients } \\
\text { Age 56-66 } \\
\mathrm{n}=3\end{array}$ & $58.3 \pm 3.16$ & $72.3 \pm 3.48^{\circ}$ \\
\end{tabular}

Results are expressed as $\mathrm{nM} / \mathrm{mg}$ protein/min. Each value is the mean value $\pm S$. D. of independent determinations from n. patients, carried out in triplicate.

$\mathrm{n}=$ number of patients; ${ }^{\circ} P<0.001$ treated versus untreated.

(27-years old) the $\mathrm{AChE}$ activity is localized in the wall of an arteriola (A), of a venula (V), of two lymphatic vessels (arrow) and in many reticular cells. At this age, the human thymus shows the signs of a histological involution (Magnification $200 \times$ ).

Fig. 2 must be compared with Fig. 1. The sample comes from a young patient (28 years of age) previously immunostimulated with interferon
Table 3 Quantitative analysis of images (QAI) of the $A C h E$ levels in thymic biopsies from adult and old patients treated and untreated with interferon

\begin{tabular}{lcc}
\hline \multicolumn{1}{c}{ Thymus } & $\begin{array}{c}\text { Untreated } \\
n=7\end{array}$ & $\begin{array}{c}* \text { Treated with interferon } \\
n=7\end{array}$ \\
\hline $\begin{array}{l}\text { Adult patients } \\
\text { Age 24-55 } \\
n=4\end{array}$ & $18.3 \pm 1.4$ & $26.4 \pm 1.9^{\circ}$ \\
\hline $\begin{array}{l}\text { Old patients } \\
\text { Age 56-66 } \\
n=3\end{array}$ & $30.1 \pm 2.2$ & $36.4 \pm 2.3^{\circ}$ \\
\end{tabular}

Results are expressed in Conventional Units (C. U.-see methods) \pm S. E. M. The analyzer was calibrated considering "zero" the values of control section incubated without substrate or in presence of specific inhibitors. For other precautions see methods. $P$ was calculated comparing the significant differences between treated and untreated patients. n $=$ number of patients; ${ }^{\circ} P<0.001$ treated versus untreated.

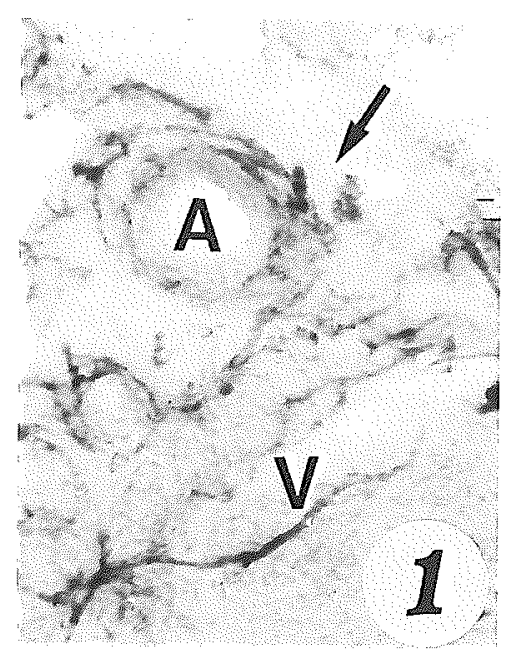

Fig. 1 AChE activity in the human thymus of a young not immunostimulated healthy man (27-years old). Cortical zone. Despite the thymic involution the wall of an areriola (A), a venula (V) and two lymphatic vessels (arrow) shows a positive reaction. Many reticular cells show also a positive reaction (Magnification $200 \times$ ).

drugs. This photograph shows a strong positive reaction for $\mathrm{AChE}$ activity localized in reticular cells (R) and in the wall of an arteriola (A), a venula (V) and a lymphatic vessel (L) (Magnifica- 


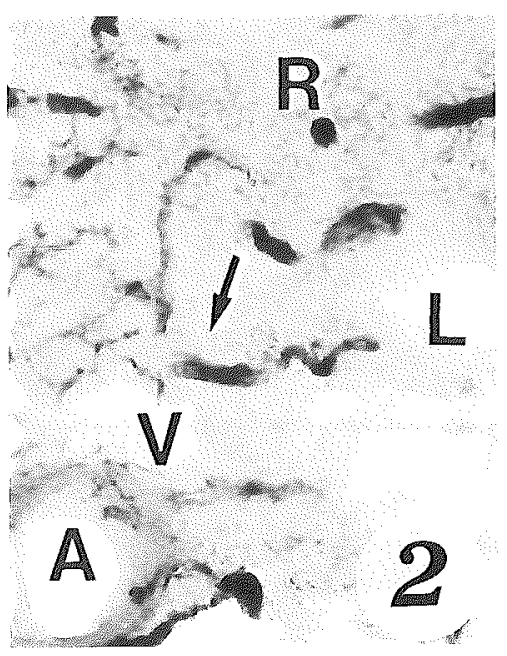

Fig. 2 AChE activity in the human thymus of a previously immunostimulated young man (28-years old). Cortical zone. The wall of an arteriola (A), a venula (V) and a lymphatic vessel (L) shows a positive reaction. Many nerve fibers (recognized by Bodian's reaction) show a positive reaction (arrows). Numerous reticular cells (R) show also a positive reaction (Magnification $200 \times$ ).

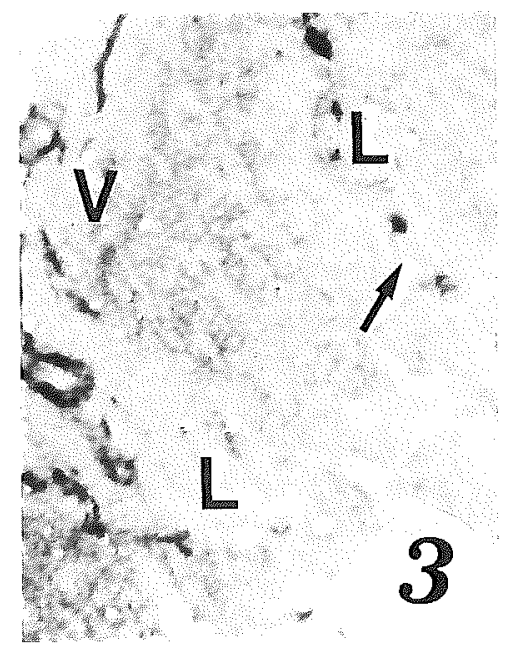

Fig. 3 AChE activity in the human thymus of an elderly not immunostimulated healthy man (60-years old). Cortical zone. The thymic structures show an evident involution. The wall of a venula (V) and of many lymphatic vessels ( $L$ ) show a positive reaction. Many reticular cells $(\mathrm{R})$ show also a positive activity (Magnification 200X).

tion $200 \times)$.

Many nerve fibers (recognized by Bodian's method) also show a positive reaction (arrows).

Fig. 3. In an untreated elderly man (60 years of age) only a venula (V) and many lymphatic vessels show a positive staining for the AChE activity. All the thymic structures show a clear involution. Structures resembling nerve fibers show a positive reaction (arrows-Magnification $200 \times)$.

In Fig. 4 we can observe strong positive enzymatic staining in many structures resembling nerve fibers (arrows). A corpuscle of Hassall (H), the wall of an arteriola $(A)$ and the wall of a venula (V) show a positive reaction for $A C h E$ activity. The samples of thymus were taken from an elderly man (age 66 years) previously immunostimulated with interferon drugs (Magnification $200 \times$ ). On comparing Fig. 3 with Fig. 4 it is evident that immunostimulation of the thymus with interferon drugs induces an increase of AChE activity.

In Fig. 5 we can observe a transverse section of the human thymus. Sample was obtained from an adult patient (50 years old). AChE activity appears as dark precipitates (arrows) around a Hassall's corpuscle $(\mathrm{H})$. Hassall's corpuscles are recognized as an expression of thymic involution. The corpuscle imaged in Fig. 5 is formed by concentric epithelial lamellae and also shows a positive reaction for $\mathrm{ACh} \mathrm{E}$. The thymic structures positive for AChE activity increase with age in accordance with the increase of the total amount of AChE demonstrated after biochemical dosage

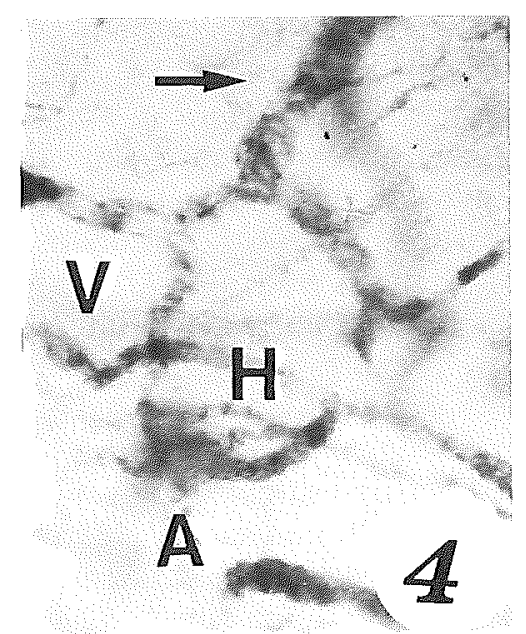

Fig. 4 AChE activity in the human thymus of a previously immunostimulated elderly man (66years old). Cortical zone. We can observe a strong reaction in many thick nerve fibers (arrows) recognized also by Bodian's staining (Magnification $200 \times$ ). 


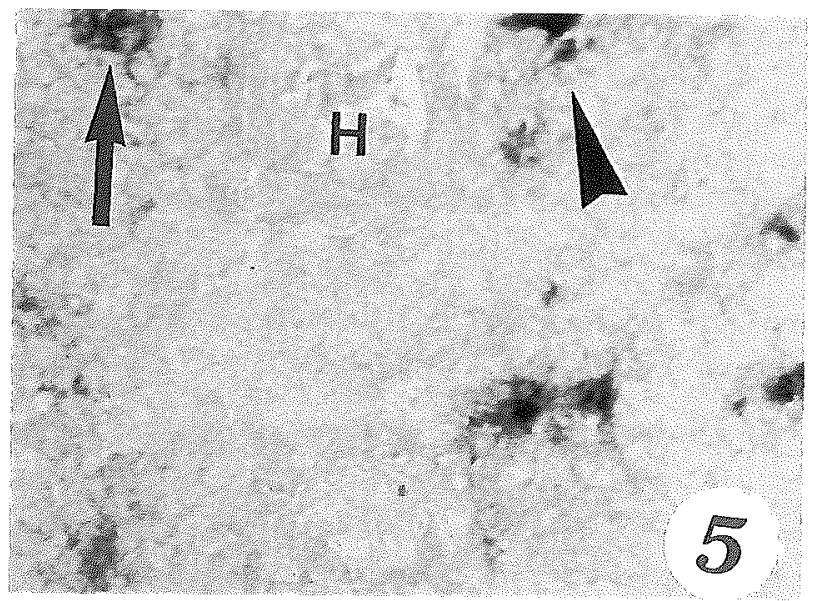

Fig. 5 Transverse section of human thymus. Sample was obtained from an adult patient (50-years old). Acetylcholinesterase activity appears as dark precipitates (arrows) around a Hassall's corpuscle $(H)$ that shows a mildly positive reaction. Hassall's corpuscles are an expression of thymic involution (Magnification $400 \times$ ).

\section{(see below).}

After immunostimulation with interferon drug the thymus of an adult patient (52 years old) shows an increase of AChE-positive structures (Fig. 6). AChE activity appears as dark precipitates (arrows) organized in thick beads distributed in close relation to the reticular cells (R). The coarse granular dark precipitates correspond to the $A C h E$ reaction. Our other results are reported in Tables 1-3.

Table 1 displays the results of protein content in homogenates of the thymus in adult or elderly patients either treated or untreated with interferon. As can be seen, therapeutic treatment with interferon drugs modifies the protein content of thymic homogenates both in adult and in elderly patients. In fact, in untreated adult patients the protein level, expressed as $\mathrm{mg} / \mathrm{g}$ fresh tissue weight, is $15.8 \mathrm{mg}$ while in treated adult patients this level goes up to $19.6 \mathrm{mg}$ with a highly positive (treated versus untreated) significance coefficient $(P<0.001)$. Moreover, in elderly untreated patients the thymus protein content is $10.4 \mathrm{mg} / \mathrm{g}$ fresh tissue weight. It goes up to $12.8 \mathrm{mg} / \mathrm{g}$ fresh tissue weight in the thymus of patients treated with interferon drugs, with a positive coefficient of significance, despite the limited number of samples examined ( 3 treated and 3 untreated). Table 2 deals with the values of biochemical dosages of $\mathrm{AChE}$ activity in the supernatant of

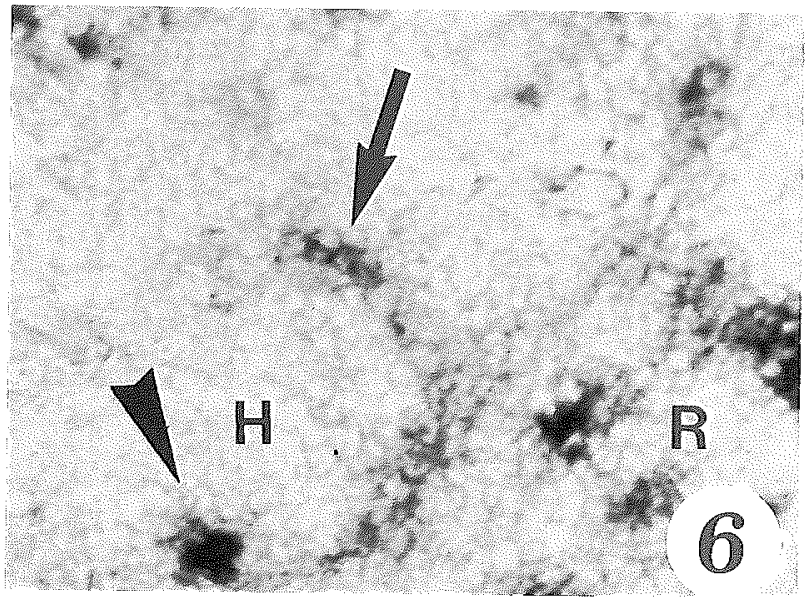

Fig. 6 Transverse section of human thymus. Sample was obtained from an adult patient (52-years old) after treatment by interferon drug. AChE activity appears as dark precipitates (arrows) organized in thick beads that encircle a Hassall's corpuscle $(H)$ or appears to be distributed around reticular cells ( $\mathrm{R}$ ) (Magnification $400 \times$ ).

thymus homogenate from adult and elderly patients treated and untreated with interferon. Results are expressed as $\mathrm{nmol} / \mathrm{mg}$ protein $/ \mathrm{min}$. In untreated adult men $(n=4)$ the mean value was 36.3. It rose to 51.4 in patients treated with interferon. In untreated elderly men $(n=3)$ the mean value was 58.3. It rose to 72.3 in those treated with interferon. On comparing the significant differences between treated and untreated patients, the significance coefficient appears highly positive $(P<0.001)$.

Table 3 shows the results of quantitative image analysis of $\mathrm{AChE}$ levels in biopsies of the thymus from adult and elderly patients in treated or untreated subjects. The mean value in four untreated adult patients was 18.3. It rose to 26.4 in four treated adult patients.

In three untreated elderly patients the mean value of $\mathrm{AChE}$ levels was 30.1 , rising to 36.4 in patients of the same age treated with interferon. These results show that during the immune response the level of AChE is increased.

The biochemical data together with the histoenzymatical results provide evidence for a specific localization of AChE activity in the thymic gland. Moreover, the immune response modifies the levels of AChE. The AChE-positive structures of the human thymus increase with age, exceeding the reduction of the thymic volume due to involution. The density of AChE-positive structures in 
human thymus correlates inversely with its volume. The AChE-positive thymic structures are not confined to the extraparenchymal compartment, but they also reach the thymic microenvironment.

Patients treated with interferon, a potent promoter of the immune response, show high levels of AChE-positive structures (in comparison with untreated patients).

Many of these AChE-positive structures can be recognized as nerve fibers after specific staining with the method of Bodian. According to our results major AChE-positive structures appear to be vessels and reticular cells.

Other AChE-positive structures are recognized as thymic cells (or lymphoepithelial cells or thymocytes) after staining with Eosin orange.

Additional AChE-positive structures can be identified as reticular cells or as corpuscle of Hassall or as wall of arterioles, venules or lymphatic vessels.

\section{DISCUSSION}

The present results provide direct evidence about the cellular localization of AChE activity in the human thymus and its elevation in interferonstimulated conditions. Treatment with interferon is also capable of increasing the protein content of the thymus. Taking into consideration the biochemical data together with the histoenzymatical results, there is evidence for a specific localization of AChE activity in the thymic gland. The AChE activity of the thymus, expecially after treatment with interferon, is localized particularly in the lymphatic cells and in the vascular and lymphatic network of the human thymus. The presence of AChE activity in thymic vessels and in thymic reticular cells is not an original and now finding of the present study. In fact, parasympathetic innervation of the rat thymus was studied by al-Shawaf and coworkers (18). Parasympathetic innervation was found to enter the thymic gland with the vasculature and to distribute to both cortex and medulla. AChEpositive staining cells were seen in the medulla. These results were confirmed by Micic and coworkers (15). These Authors found AChEpositive nerve profiles in the subcapsular region, mainly in close proximity of the thymic epithelial cells, while in the cortico-medullary region they were found in apposition to the thymocytes. The AChE activity in those thymic cells may act as a catabolic enzyme regulating the breakdown process of $\mathrm{ACh}$ released from nerve terminals or otherwise as a neurotransmitter, because the target cells possess specific receptors (21).

Owing to the strong localization of $\mathrm{AChE}$ activity in the vascular and lymphatic network of human thymus and also in the lymphatic cells (treated or untreated with interferon), it is possible to study the intrathymic lymphatic and vascular network by means of our experimental results obtained from serial sections and from QAI.

Human thymus has a rich network of lymphatic vessels. The roots of this network have been demonstrated in the parenchyma and in the connective tissue forming the septa between lobules. Coming from the septa, lymphatic vessels run toward the capsule of the gland and, as efferent lymphatic vessels, mainly reach the anterior mediastinal and tracheo-bronchial lymph nodes. However, an evident intrathymic lymphatic network cannot be defined. In the thymic lymphoid tissue the follicles and the prolipherative lymphoid areas themselves (typical of lymph nodes) are not visible.

The thymic medulla is not characterized by lymphatic sinusoids. Moreover, clear anatomical relationships with the capsular lymphatic network also appear to be absent. In fact, the same perivasal areas represent the initial root of the intrathymic lymphatic network.

The morphology of the thymus is also marked by the characteristic Hassall's corpuscles (clusters of cells encircled by typical laminae having uncertain functional significance, but recognized as an expression of thymic involution).

"Perivasal spinnings" are the thymic structures forming a particular functional barrier that allows the separation of the thymic microenvironment from the circulating antigens. Treatment with interferon induces an immune response. This response can be verified by means of biochemical dosages demonstrating an increase of circulating antibodies.

In our patients, the efficiency of immunostimulating therapy was controlled by means of common laboratory tests performed during hospitalization.

A significant rise in thymic AChE levels was found after treatment with interferon. The possible biological significance of this elevation can be considered. It is possible that the increase in AChE activity may accelerate the catabolism of 
the acetylcholine (ACh) bound with AChreceptors. It induces an increase of the active state of the $\mathrm{ACh}$ receptors. These receptors may be stimulated by the activity of the parasympathetic nervous system and may modulate some functions of thymocytes (21).

Thymic cells that synthesize thymosin possess also cholinergic receptors. The AChE-positive structures of the thymus, acting on these receptors, may stimulate the thymosin production.

Our results demonstrate that patients treated with interferon, a potent promoter of the immune response, show higher levels of $\mathrm{AChE}$ activity in thymic tissues (in comparison to untreated patients). Moreover, the immune response increases the level of AChE-positive structures contained in the human thymus. A specific localization of AChE has been found by biochemical and histoenzymatic methods in structures resembling nerve fibers and/or in lymphatic structures of the thymic gland. Toyabe et al. (21) proposed a view that lymphocytes carry nicotinic ACh receptor (nAChR) on the surface. These receptors are able to bind $\alpha$-bungarotoxin, are the same as those of the skeletal muscle and are stimulated directly via their nAChR by parasympathetic nerve stimuli in the thymus in mice. The same mechanism may be involved in the increasing of $\mathrm{AChE}$ levels in structures resembling nerve fibers and/or in the lymphatic structures of the thymic gland during the immune response. The AChEpositive structures of the thymus may act on these receptors stimulating the thymosin levels even in man, as just said.

Treatment with interferon is also capable of increasing the protein content of the thymus. Our biochemical data together with histoenzymatic qualitative and quantitative results, provide direct evidence for a specific localization of AChE activity in the thymic gland. Moreover, lymphatic vessels, reticular cells, epithelial cells and structures resembling nerve fibers of the thymus show a positive $\mathrm{AChE}$ staining.

\section{Acknowledgements}

The present study was supported by a grant from University "La Sapienza" of Rome. The Authors are greatly indebted to Drs M. A. Aita and M. Kovacs for their useful suggestions and criticisms. The technical assitance of Mr Dario Caporuscio, the excellent secretarial work of Mrs Silvana Casamento, the photographic assistance of $\mathrm{Mr}$
Giuseppe Leoncini and the kind help of Mrs Sharon Hobby in the revision of the English language are also gratefully acknowledged.

\section{REFERENCES}

1. Bodian D. (1936) A new method for staining nerve fibers and nerve endings in mounted paraffin sections. Anat. Record. 65, 89-97.

2. Castino M, Roletto E. (1992) Statistica Applicata. Padua, Piccin ed.

3. Cavallotti D, Artico M, Iannetti GD, Cavallotti C. Quantification of acetylcholinesterase-positive structures in human thymus during development and age. Nettrochem. Internat. (in press).

4. Cavallotti C, Artico M, Cavallotti D, Tranquilli Leali FM, Frati A. (1999) Distribution of acetylcholinesterase activity in thymus of juvenile and aged rats. Biomed. Res. 20, 73-80.

5. de Leeuw FE, Jansen GH, Batanero E, van Wichen DF, Huber J, Schuurman HJ. (1992) The neural and neuroendocrine component of the human thymus. I. Nerve-like structures. Brain Behav. Immun. 6, 234-248.

6. Du Bois KP, Dull J, Coon JM. (1950) Studies on the toxicity and pharmacological action of octamethylpyrophosphoramide (OMPA, Pestox III). J. Phamacol. Experim. Ther. 99, 376-393.

7. Ellman GL, Courtly KD, Andres V Jr, Featherstone RM. (1961) A new and rapid colorimetric determination of acetylcholinesterase activity. Biochem. Pharmacol. 7, 88 89.

8. Hori T, Katafuchi $T$, Take $S$, Shimizu N, Niijima A. (1995) The autonomic nervous system as a communication channel between the brain and the immune system. Neuroimmunomodulation 2, 203-215.

9. Karnowsky MJ, Roots L. (1964) A direct colouring thiocholine method for cholinesterase. J. Histochem. Cytochem. 12, 219-221.

10. Lowry OH, Rosebrough NJ, Farr AL, Randall J. (1951) Protein measurement with the Folin phenol reagent. $J$. Biol. Chem. 193, 265-275.

11. Mackey I. (1972) Aging and immunological function in man. Gerontologia 18, 285-304.

12. Makinodan T. (1976) Immunology of aging. J. Am. Geriatr. Soc. 24, 249-252.

13. Martin-Fontecha A, Broekhuizen R, de Heer C, Zapata A, Schuurman HJ. (1993) The neuro-endocrine component of the rat thymus: studies on cultured thymic fragments before and after transplantation in congenitally athymic and euthymic rats. Brain Behav. Immun. 7, 1-15.

14. Meites J, Goya R, Takahashi S. (1987) Why the neuroendocrine system is important in aging processes. A review. Exp. Gerontol. 22, 1-12.

15. Micic M, Leposavic G, Ugresic N, Bogojevic M, Isakovic K. (1992) Parasympathetic innervation of the rat thymus during first life period: histochemical and biochemical study. Thymus 19, 173-182.

16. Patrick WLA, Besley GTN, Smith IJ. (1980) Histochemical diagnosis of Hirschprung's disease and a comparison of the histochemical and biochemical activity of acetylcholinesterase in rectal mucosal biopsies, J. Clin. Pathol. 33, 336-343.

17. Serio A. (1986) Appunti dalle lezioni di Statistica Sani- 
taria. Rome, Kappa ed.

18. al-Shawaf AA, Kendall MD, Cowen T. (1991) Identification of neural profiles containing vasoactive intestinal polypeptide, acetylcholinesterase and catecholamines in the rat thymus. J. Anat. 174, 131-143.

19. Smith EM, Blalock JE. (1988) A molecular basis for interactions between the immune and neuroendocrine systems. Int. J. Neurosci. 38, 455-464.

20. Townsend FM. (1960) Mamual of histologic and special staining techniques. New York, Mc Graw-Hill.

21. Toyabe S, Iiai T, Fukuda M, Kawamura T, Suzuki S, Uchiyama M, Abo T. (1997) Identification of nicotinic acetylcholine receptors on lymphocytes in the periphery as well as thymus in mice. Immunology 92, 201-205.

22. Weihe E, Nohr D, Michel S, Mueller S, Zentel HJ, Fink T, Krekel J. (1991) Molecular anatomy of the neuro-immune connection. Int. J. Neurosci. 59, 1-23.iol. 3, 2271-2279. 